\title{
Treatment of Aortic Graft Infection with Cryopreserved Aortic Allografts
}

\author{
AUDRA A. NOEL, M.D., PETER GLOVICZKI, M.D., \\ KENNETH J. CHERRY, JR., M.D., DAVID G. HAN, M.D., and \\ JEROME F. BREEN, M.D.
}

ABSTRACT Reconstruction alternatives following removal of an infected aortic graft bear a high morbidity and mortality rate. Recent reports suggest that cryopreserved tissue may be implanted in infected fields and, therefore, may be suitable for replacement of infected aortic grafts. We report two cases of aortic replacement with cryopreserved allografts. Case 1: A 60-year-old woman presented with 6 months of right groin pain and a 30-1b. weight loss. She underwent aortobifemoral bypass in 1981 for occlusive disease, with revisions in 1983 and 1985. Computed tomography (CT) and indium-111 WBC scan suggested aortobifemoral graft infection. The aortobifemoral graft was removed and replaced with a cryopreserved aortoiliac allograft. Postoperatively, she had a left hemispheric stroke with right arm weakness. She recovered well, and 7 months later was doing well, with palpable distal pulses and no evidence of recurrent infection on CT scan. Case 2: Two years after placement of an aortobiiliac graft for aneurysmal disease, a 77-year-old man presented with sequelae of septic emboli. There was no fat plane between the proximal graft and small bowel on CT scan. Indium-111 WBC scan suggested aortic graft infection. Abdominal exploration confirmed aortic graft-enteric erosion, with a defect in the proximal jejunum, which was repaired. The infected graft was removed and the aorta replaced with a cryopreserved aortic allograft. He had

A.N., Assistant Professor of Surgery, Division of Vascular Surgery, Mayo Clinic; P.G., Professor of Surgery, Mayo Medical School; Chair, Division of Vascular Surgery, Mayo Clinic; K.J.C., Consultant, Division of Vascular Surgery; Professor of Surgery, Mayo Medical School, Mayo Clinic, Rochester, MN; D.G.H., Associate in Vascular Surgery, Geisinger Medical Center, Danville, PA; J.F.B., Assistant Professor of Radiology, Mayo Medical School, Mayo Clinic, Rochester, MN.

Copyright ( $) 2000$ by Thieme Medical Publishers, Inc., 333 Seventh Avenue, New York, NY 10001, USA

Tel.: +1(212) 584-4662. 0894-8046,p;2000,13,2,55,64,ftx,en; pvs00097 
no postoperative complications. Thirteen months after surgery, he is asymptomatic, without complications or evidence of infection on CT or WBC scans. Aortic cryopreserved allografts may be a feasible alternative for replacement of infected aortic grafts. Our early experience has been promising, but long-term follow-up is necessary to assess secondary aneurysmal or thrombotic changes in these grafts.

\section{Keywords Infection, aortic graft, cryopreservation, allograft}

Aortic graft infection remains a devastating complication associated with high mortality and amputation rates. Removal of the infected graft and replacement with an extra-anatomic bypass may be associated with limb loss, aortic stump blow-out, or pelvic ischemia, ${ }^{1-3}$ whereas antibiotic-soaked in situ polyester grafts may become re-infected, especially when placed in patients with abscesses. ${ }^{4}$ Aortic reconstruction with saphenous or deep lower limb veins is associated with prolonged operative time and possible venous morbidity. ${ }^{5}$ Potential advantages of aortic graft replacement with cryopreserved allografts include easy availability, avoidance of deep vein excision, the ability to maintain pelvic blood flow with in situ replacement, and proposed reduced re-infection rates. We report two cases of aortic replacement with cryopreserved aortic allografts.

\section{CASE REPORTS}

\section{Case 1}

A 60-year-old woman, status post-aortobifemoral bypass in 1981 for occlusive disease, with revisions in 1983 and 1985, presented with right groin pain. She was afebrile and had excellent distal pulses. Laboratory values were normal, including a white blood cell (WBC) count of $7,400 \times 10^{9}$ cells/L and negative blood cultures. Computed tomography (CT) showed minimal peri-graft soft tissue and indium-111 WBC scan demonstrated slight increase in uptake predominantly in the left groin. She was initially treated with oral antibiotics, but had reoccurrence of her groin pain and persistent weight loss over the subsequent six months. Repeat CT (Fig. 1A) and WBC scans (Fig. 1B) were consistent with a progressive aortobifemoral graft infection. Aortography confirmed a patent graft with bilateral superficial femoral artery stenoses.

The patient underwent graft removal after placement of ureteral stents. Purulent fluid containing many WBCs surrounded both femoral limbs and the aortic graft. A donor $40 \mathrm{~mm}$ bifurcated cryopreserved aortic graft was initially thawed at $37-42^{\circ} \mathrm{C}$ for $15-25$ minutes in a large basin. Because additional length was required, a $42-\mathrm{cm}$ cryopreserved femoro-popliteal segment was also prepared using serial dilutions designed to elute the cryopreservation 

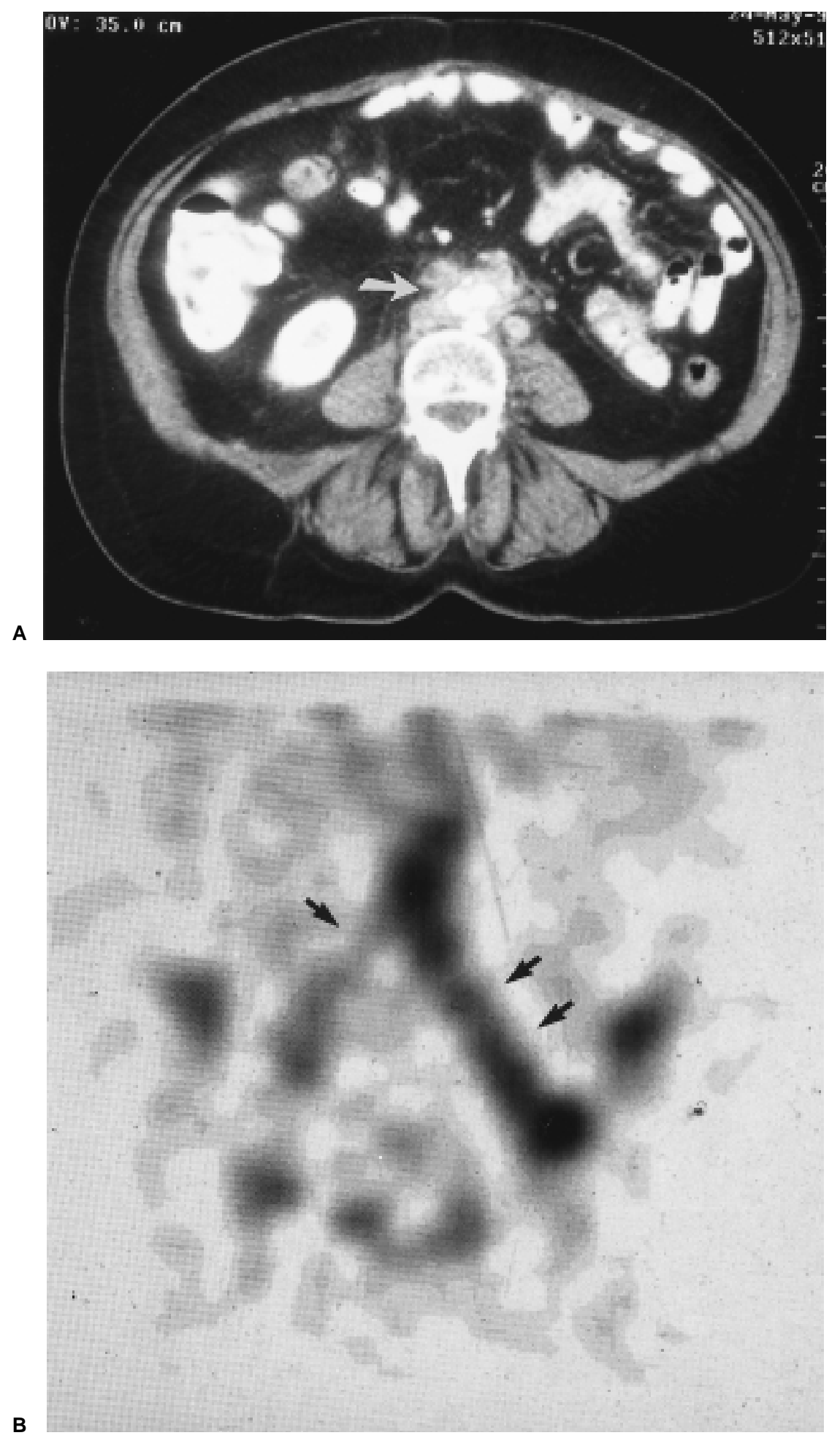

Fig. 1 (A) CT scan of a 60 year-old woman demonstrates soft tissue inflammation around the aortic graft (arrow). (B) WBC scan performed at the same time showed uptake of radioactive precursor in the aortic graft and both the right (arrow) and left graft limbs (double arrows) suggestive of an infected aortobifemoral prosthetic graft. 
solution without destroying the integrity of the graft. The femoro-popliteal segment was divided and sutured to the aorto-iliac segment. (Fig. 2) After removal of the infected aortobifemoral graft, the allograft was sutured endto-end to the infrarenal aorta and to the distal common femoral, profunda femoris, and superficial femoral arteries bilaterally (Fig. 3) and the graft wrapped with omentum. Ultrasonic flow measurements were 450 and 400 $\mathrm{ml} / \mathrm{min}$ in the left and right limbs, respectively.

Although all tissue cultures were negative, the patient was maintained and discharged on antibiotics. Postoperatively, she had a left hemispheric stroke with right arm weakness. She recovered well, and seven months later is doing well, with palpable distal pulses and no evidence of recurrent infection by clinical exam, CT scan, or WBC scan.



Fig. 2 Preparation of the aortobifemoral cryopreserved graft. A femoropopliteal cryopreserved graft was divided in half and each segment anastomosed to the iliac limbs of the aorto-iliac cryopreserved graft. These additional segments allowed the graft to extend from the patient's aorta to her femoral arteries. 


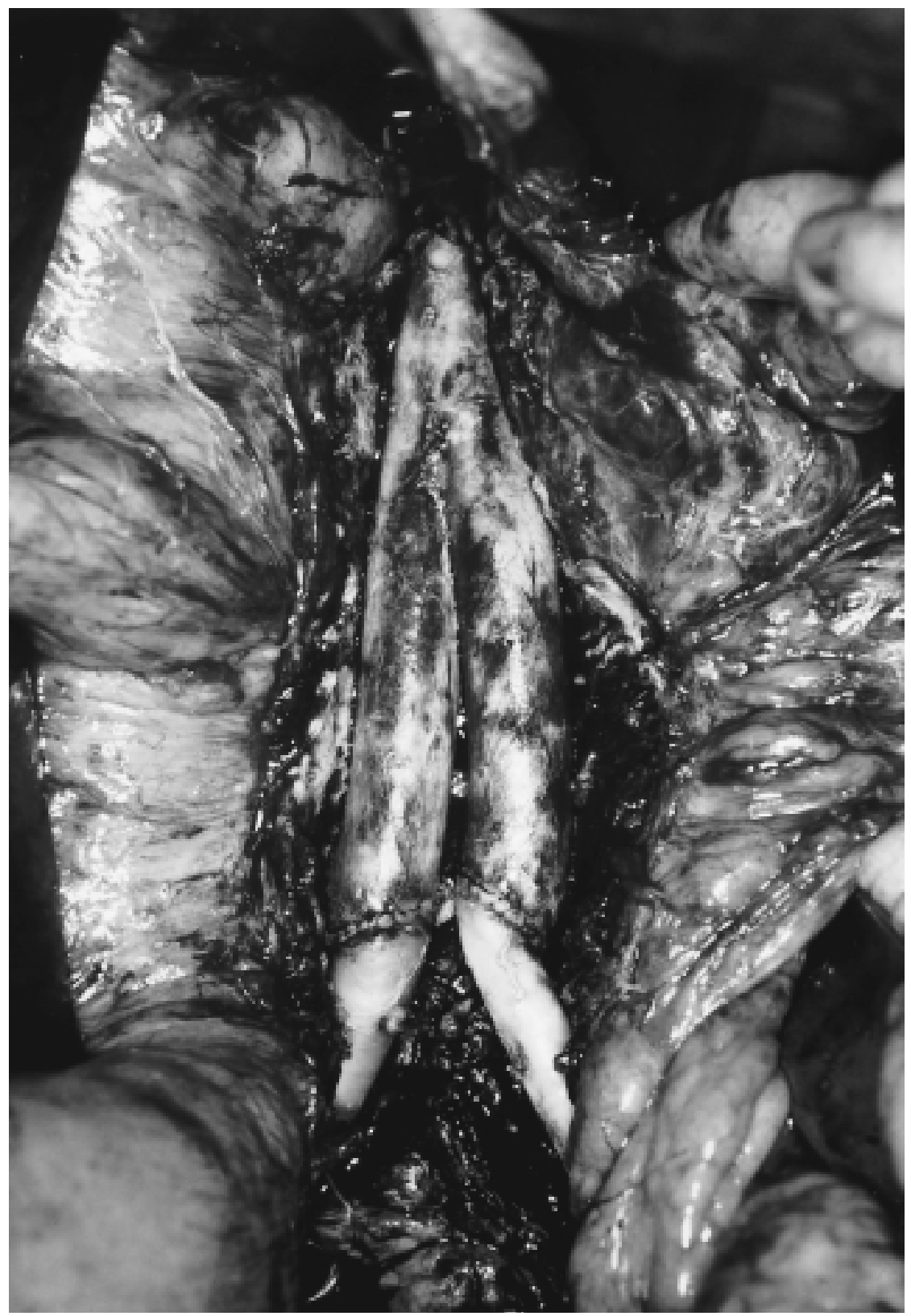

Fig. 3 After removal of the infected graft, the cryopreserved allograft was anastomosed end-to-end to the infrarenal aorta and end-to-side to both femoral arteries.

\section{Case 2}

Two years after placement of an aortobi-iliac graft for aneurysmal disease, a 77-year-old man presented with nine months of fever, chills, bacteremia, 
and episodes of foot and thigh abscesses requiring drainage, consistent with septic emboli. CT scan (Fig. 4) demonstrated no fat plane between the small bowel and aorta with soft tissue containing gas bubbles overlying the perirenal aorta. WBC scan also was suggestive of aortic graft infection, and aortogram showed a patent graft with kinking of the iliac limbs.

After placement of ureteral stents, abdominal exploration confirmed aortic graft-jejunum fistula (Fig. 5). The small bowel was repaired primarily with a two-layer closure and the infected graft was removed. Infected thrombus was found in the graft at the area of the jejunal erosion. The aorta was replaced with a $12 \times 5 \mathrm{~mm}, 18 \mathrm{~cm}$ long cryopreserved aortic allograft from the infrarenal aorta to both common iliac arteries. Ultrasonic flow measurements were 900 and $850 \mathrm{ml} / \mathrm{min}$ in the left and right limbs, respectively. A small rent in the left ureter was repaired over a stent. The allograft was wrapped with an omental flap.

Intraoperative cultures grew Candida albicans, Enterobacter cloacae, Bacteroides fragilis, and Veillonella parvula. He was given intravenous antibiotics for six weeks and converted to lifelong oral antibiotics. He had no postoperative complications and was dismissed 14 days after surgery. Thirteen months after the operation, he is asymptomatic, without complications or evidence of infection on CT scan or WBC scan.

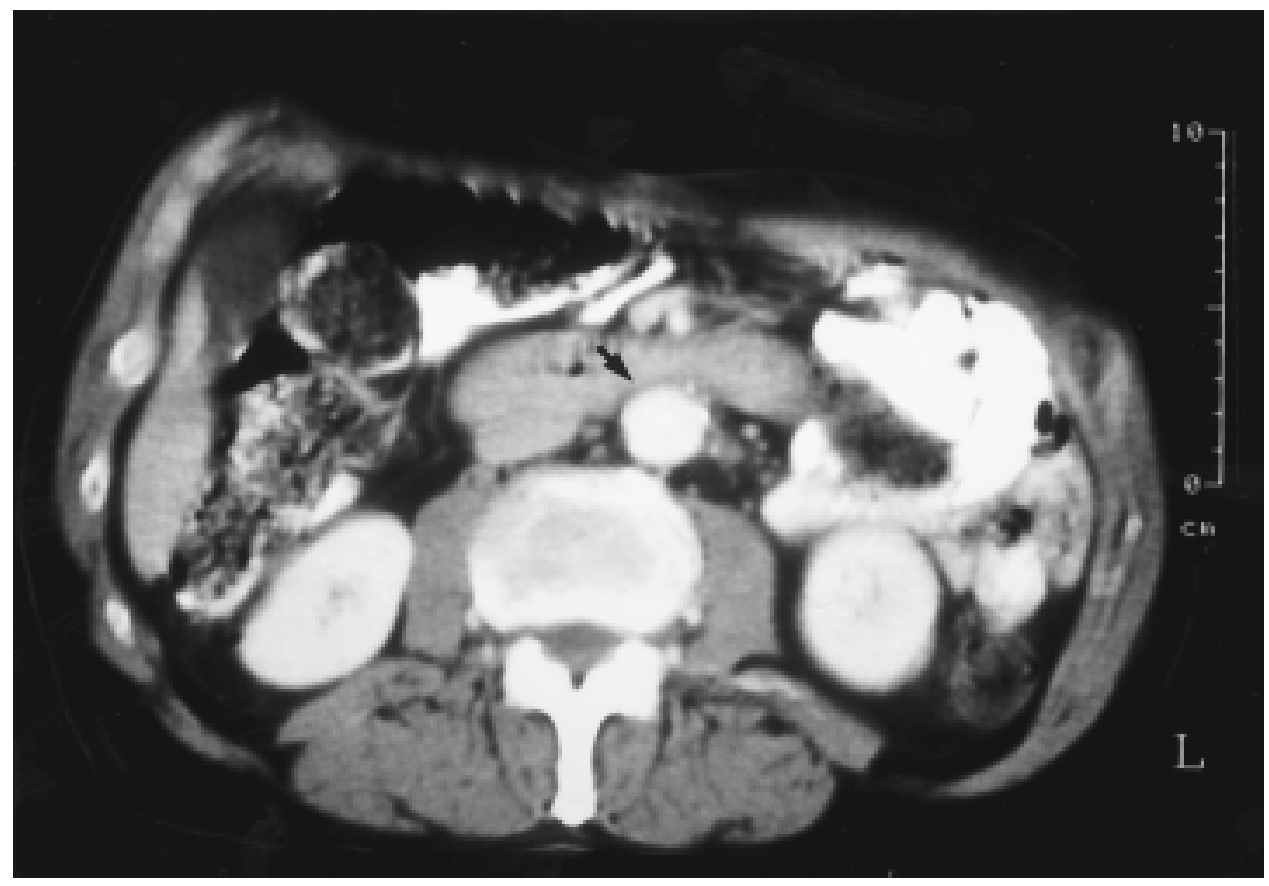

Fig. 4 CT scan of a 77-year-old man demonstrates loss of the tissue plane between the aortic graft and the overlying small bowel (arrow) suggestive of aorto-enteric fistula. 


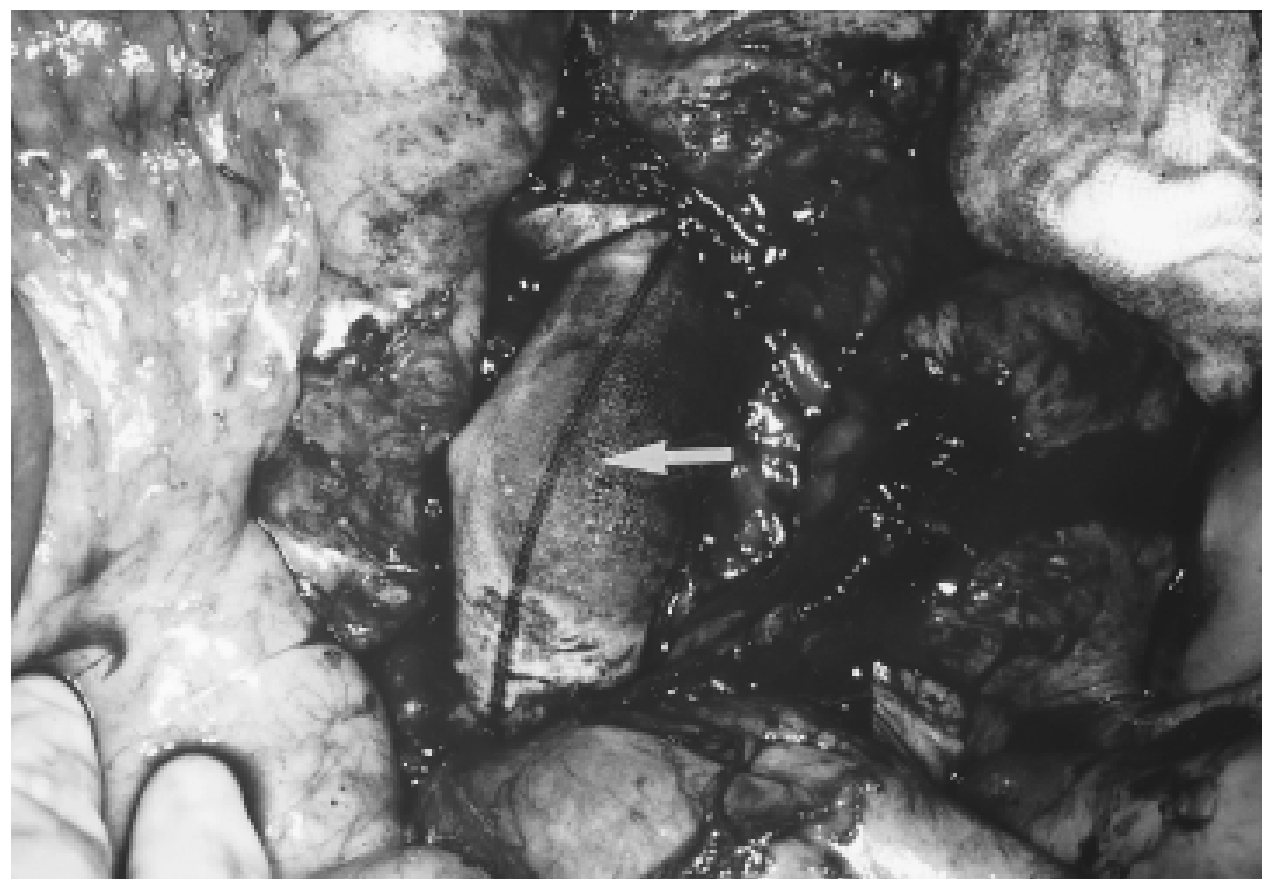

Fig. 5 The polyester graft was bile-stained (white arrow) due to an aorto-enteric fistula with a large defect in the jejunum.

\section{DISCUSSION}

Options for management of aortic graft infection include extra-anatomic bypass with resection of the infected graft, ex situ retroperitoneal aortic bypass, ${ }^{6}$ nonresectional strategies such as antibiotic irrigation, 7 in situ graft replacement with antibiotic-soaked graft, or in situ graft replacement with arterial allograft. Despite multiple management options, the mortality of aortic graft infection remains high $(20-50 \%)^{1,2,4,8}$ This summary of two patients undergoing cryopreserved allograft replacement for an infected aortic graft represents a potential management option with low morbidity and easy availability.

Extra-anatomic bypass with resection of the graft often is described as the gold standard of treatment for aortic graft infection. ${ }^{9,10}$ This approach may be complicated by aortic stump blowout or axillofemoral graft thrombosis or infection. A recent series from Yeager reported 60 patients who underwent axillofemoral bypass followed by excision of the infected aortic graft. 9 The perioperative mortality rate was $13 \%$ and 5 -year primary axillofemoral graft patency was $73 \%$. Although there were no reported cases of aortic stump blowout in Yeager's series, this remains a potential, lethal complication. In addition, reduced graft patency remains a concern, especially in younger 
patients receiving an extra-anatomic bypass. A series of 16 patients from Darling et al., suggested retroperitoneal in-line aortic bypass through un-infected tissue planes may offer the benefit of extra-anatomic bypass without the lower patency associated with axillofemoral bypass. ${ }^{6}$ Thirty-day mortality rate was $0 \%$ and limb salvage was $100 \%$. With a mean follow-up of 32 months, no re-infection was noted. Although this technique may be a reasonable option, larger series with longer follow-up will be needed.

In-situ graft replacement with antibiotic-soaked graft is a feasible option. Of 52 patients with aorto-enteric fistula treated at our institution, 10 patients underwent in situ aortic replacement. ${ }^{8}$ Of these 10 patients, 30 -day surgical mortality was $50 \%$ after emergency repair and $17 \%$ after elective repair. One patient required early amputation, and none of the seven early survivors had evidence of infection at last follow-up. A recent series from our institution reported the results of 25 patients treated for aortic graft infection with $8 \%$ mortality and $100 \%$ limb salvage rate. ${ }^{4} \mathrm{~A}$ trend of lower re-infection was noted with rifampin-impregnated grafts and patients with aortoenteric fistulae, and those without abscesses had improved overall results. This series emphasized the importance of graft coverage with autogenous tissue, as a 360-degree graft wrap conferred significant protection from re-infection. The Leicester experience of in situ graft replacement suggested methicillinresistant staphylococcus aureus (MRSA) was associated with poor prognosis after in situ graft replacement. ${ }^{11}$

Initial experience with cryopreserved allografts has been documented for aortic valve homografts with generally positive results. ${ }^{12-15}$ However, the experience with in situ replacement of cryopreserved allograft for infected aortic grafts still is limited. Kieffer's large series of aortic allografts were stored at $4^{\circ} \mathrm{C}$, which clearly is different from currently used cryopreserved allografts, stored at -180 to $-196^{\circ} \mathrm{C}$. Kieffer reported $18 \%$ mortality in a series of 83 patients, who underwent in situ replacement of infected aortic grafts (Table 1). ${ }^{16}$ Four (5\%) patients had late dilation of their allograft segment and $15(18 \%)$ patients had late occlusive lesions.

Cryopreserved grafts are reported to demonstrate reduced antigenicity and improved cellular integrity as compared to fresh homografts. This theory is supported by the data from both Vogt and Chiesa (Table 1), who report surgical mortality from 6-13\% in patients receiving cryopreserved aortic allografts. ${ }^{14,15}$ In addition, experimental animal studies suggest that cryopreserved grafts may be more resistant to reinfection. Furthermore, graft rejection is rare, immunosuppression is not required, and allografts are readily available. However, da Gama describes histologic degeneration of the media in cryopreserved grafts, leading to secondary aneurysmal or thrombotic changes. ${ }^{17}$ Because of these histologic changes, cryopreserved grafts may not be effective long-term solutions, but may be considered as a bridge to allow resolution of infection prior to in situ prosthetic graft replacement. Other potential limitations of cryopreserved grafts include rejection, lack of 
Table 1 Results of Aortic Allografts

\begin{tabular}{|c|c|c|c|c|c|}
\hline \multirow{2}{*}{$\begin{array}{l}\text { Author, } \\
\text { Year }\end{array}$} & No. of patients & $\begin{array}{l}\text { 30-day } \\
\text { surgical } \\
\text { mortality }\end{array}$ & $\begin{array}{l}\text { Overall } \\
\text { mortality }\end{array}$ & Mean follow-up & $\begin{array}{l}\text { Resolution } \\
\text { of infection }\end{array}$ \\
\hline & Type of graft & $\begin{array}{l}\text { No. of } \\
\text { patients (\%) }\end{array}$ & $\begin{array}{l}\text { No. of } \\
\text { patients (\%) }\end{array}$ & Months (range) & $\begin{array}{l}\text { No. of } \\
\text { patients (\%) }\end{array}$ \\
\hline Vogt & 34 & $2(6)$ & $6(12)$ & $24.5(10-83)$ & $31(91)$ \\
\hline 1998 & Cryopreserved & & & & \\
\hline Chiesa & 31 & $4(13)$ & $3(10)$ & $15(1-33)$ & $31(100)$ \\
\hline 1998 & Cryopreserved & & & & \\
\hline Kieffer & 83 & $15(18)$ & $26(31)$ & $\mathrm{N} / \mathrm{A}(0-72)$ & - \\
\hline 1996 & stored @ $4^{\circ} \mathrm{C}$ & & & & \\
\hline
\end{tabular}

resistance to certain bacteria, and cost. There is anecdotal evidence now of early graft hemorrhage due to reinfection or disruption of the cryopreserved graft in some patients.

Our two cases illustrate that cryopreserved allografts may be feasible alternatives for replacement of infected aortic grafts, with limited perioperative morbidity and low risk of limb loss. Although the first patient suffered a postoperative stroke, neither patient had lower extremity ischemia, limb loss, prolonged hospitalization, or evidence of re-infection at seven months after surgery. Aortic cryopreserved allografts are a potential, feasible alternative for replacement of infected aortic grafts. Rejection is rare and immunosuppression is not required. Our early experience has been promising, but long-term follow-up is necessary to assess secondary aneurysmal or thrombotic changes in these grafts.

\section{REFERENCES}

1. O'Hara PJ, Hertzer NR, Beven EG, Krajewski LP. Surgical management of infected abdominal aortic grafts: review of a 25-year experience. J Vasc Surg 1986;3:725-731

2. Reilly LM, Altman H, Lusby RJ, Kersh RA, Ehrenfeld WK, Stoney RJ. Late results following surgical management of vascular graft infection. J Vasc Surg 1984;1:36-44

3. Quinones-Baldrich WJ, Hernandez JJ, Moore WS. Long-term results following surgical management of aortic graft infection. Arch Surg 1991;126:507-511

4. Young RM, Cherry KJJ, Davis PM, Gloviczki P, Bower TC, Panneton JM, et al. The results of in situ prosthetic replacement for infected aortic grafts. Am J Surg 1999;178:136-140

5. Clagett GP, Valentine RJ, Hagino RT. Autogenous aortoiliac/femoral reconstruction from superficial femoral-popliteal veins: feasibility and durability. J Vasc Surg 1997;25:255-266 
6. Darling RC, Resnikoff M, Kreienberg PB, Chang BB, Paty PS, Leather RP, et al. Alternative approach for management of infected aortic grafts. J Vasc Surg 1997;25:106-112

7. Morris GE, Friend PJ, Vassallo DJ, Farrington M, Leapman S, Quick CR. Antibiotic irrigation and conservative surgery for major aortic graft infection. J Vasc Surg 1994; 20:88-95

8. Menawat SS, Gloviczki P, Serry RD, Cherry KJJ, Bower TC, Hallett JW, Jr. Management of aortic graft-enteric fistulae. Eur J Vasc Endovasc Surg 1997;14 Suppl A:74-81

9. Yeager RA, Taylor LMJ, Moneta GL, Edwards JM, Nicoloff AD, McConnell DB, et al. Improved results with conventional management of infrarenal aortic infection. J Vasc Surg 1999;30:76-83

10. Sharp WJ, Hoballah JJ, Mohan CR, Kresowik TF, Martinasevic M, Chalmers RT, et al. The management of the infected aortic prosthesis: a current decade of experience. J Vasc Surg 1994;19:844-850

11. Hayes PD, Nasim A, London NJ, Sayers RD, Barrie WW, Bell PR, et al. In situ replacement of infected aortic grafts with rifampicin-bonded prostheses: the Leicester experience (1992 to 1998). J Vasc Surg 1999;30:92-98

12. Bahnini A, Ruotolo C, Koskas F, Kieffer E. In situ fresh allograft replacement of an infected aortic prosthetic graft: eighteen months' follow-up. J Vasc Surg 1991;14:98-102

13. Kieffer E, Bahnini A, Koskas F, Ruotolo C, Le Blevec D, Plissonnier D. In situ allograft replacement of infected infrarenal aortic prosthetic grafts: results in forty-three patients. J Vasc Surg 1993;17:349-355

14. Vogt PR, Brunner-La Rocca HP, Carrel T, von Segesser LK, Ruef C, Debatin J, et al. Cryopreserved arterial allografts in the treatment of major vascular infection: a comparison with conventional surgical techniques. J Thorac Cardiovasc Surg 1998;116:965-972

15. Chiesa R, Astore D, Piccolo G, Melissano G, Jannello A, Frigerio D, et al. Fresh and cryopreserved arterial homografts in the treatment of prosthetic graft infections: experience of the Italian Collaborative Vascular Homograft Group. Ann Vasc Surg 1998;12:457-462

16. Koskas F, Plissonnier D, Bahnini A, Ruotolo C, Kieffer E. In situ arterial allografting for aortoiliac graft infection: a 6-year experience. Cardiovasc Surg 1996;4:495-499

17. da Gama AD, Sarmento C, Vieira T, do CG. The use of arterial allografts for vascular reconstruction in patients receiving immunosuppression for organ transplantation. J Vasc Surg 1994;20:271-278 
The group from the Mayo Clinic has added growing support for using cryopreserved allografts to treat aortic graft infections. The most common alternatives include (1) total graft excision, oversewing of the aortic stump, and placement of an axillobifemoral bypass; or (2) in situ replacement with rifampicin-soaked prosthetic grafts. The authors clearly delineate the advantages and disadvantages of all three techniques. We have employed each of these approaches with reasonably good success and tailored our approach depending on the intraoperative findings and causative organisms. We treated a patient with an infection due to Staphylococcus aureus that involved a graft originally placed for a Type III thoracoabdominal aneurysm. The patient has done well, with no evidence of infection 18 months after in situ cryograft replacement.

I believe there are three key questions concerning the use of cryopreserved allografts to treat infected aortic grafts which the authors have already considered: success of this strategy depending on the specific types of causative bacteria, results after long-term follow-up, and graft availability.

Although intraoperative fluid and tissue cultures were negative in Noel and colleagues' first case, the relationship of the causative bacteria and likelihood of success following treatment with cryopreserved allografts is critical. The authors refer to the Leicester experience where patients treated by in situ replacement with rifampin-soaked grafts did poorly when methicillin-resistant staphylococcus aureus (MRSA) was the causative organism. ${ }^{1}$ However, the results of cryopreserved allografts used when MRSA, or other virulent pathogens such as pseudomonas, is the causative organism, is not definitively known.

Other potential problems with cryopreserved allografts are aneurysmal and thrombotic graft complications after long-term follow-up. There are only a few large clinical trials using cryopreserved allografts to treat infected aortic grafts. Much of the literature concerning these grafts refer to laboratory or animal experiments..$^{2-5}$ The largest human experience in the literature using in situ replacement of cryopreserved allografts for infected aortic grafts was reported by Keiffer. ${ }^{6}$ The authors should address why the manufacturer currently stores the grafts at -180 to -196 degrees centigrade instead of 4 degrees centigrade, which was the type of graft used by Keiffer. His results were excellent, and the reader may want to know why a different process has been instituted. Was the process altered to hopefully decrease the incidence

K.D.C., Chief, Section of Vascular Surgery, Pennsylvania Hospital, Philadelphia, PA.

Copyright (C) 2000 by Thieme Medical Publishers, Inc., 333 Seventh Avenue, New York, NY 10001, USA.

Tel.: +1(212) 584-4662. 0894-8046,p;2000,13,2,65,66,ftx,en; pvs00097A 
of aneurysmal degeneration or thrombosis of the allograft? Nevelsteen reported another large series of 25 patients with aortic graft infections treated by cryopreserved allografts, and noted an admirable $11 \%$ operative mortality, but occlusive complications related to the allograft occurred in $23 \%$ of patients after approximately two years of follow-up. ${ }^{7}$

The fastest that cryopreserved grafts can be obtained from the manufacturer is approximately twenty-four hours. Since most hospitals do not stock cryopreserved allografts on their shelves, the obligatory delay in obtaining the graft may be critical depending on the type of presentation of the infection and urgency of surgical intervention.

As they have many times before, the Mayo vascular surgeons have addressed a critically important issue regarding patients with vascular disease. I applaud their efforts and encourage others to report their results with use of cryopreserved allografts to treat aortic graft infections.

\section{REFERENCES}

1. Hayes PK, Nasim A, London NJ, et al. In situ replacement of infected aortic grafts with rifampicin-bonded prostheses: the Leicester experience (1992-98). J Vasc Surg 1999;30: 92-98

2. D'Addato M, Curt T, Freyrie A, Agus GB, Bertni D, Biasi G. Prevention of early graft infection with rifampicin-bonded gelseal grafts: a multicentre experimental study. Cardiovasc Surg 1994;2:254-258

3. Goeau-Brissonniere O, Mercier F, Nicolas $\mathrm{MH}$, et al. Treatment of vascular graft infection by in situ replacement with a rifampin-bonded gelatin-sealed Dacron graft. J Vasc Surg 1994;19:739-744

4. Magnan PE, Seyral P, Raoult D, Branchereau A. In vitro antistaphylococcal activity of collagen-sealed dacron vascular prosthesis bonded with rifampin, vancomycin, or amikacin. Ann Vasc Surg 1994;8:243-247

5. Lachapelle K, Graham AM, Symes JF. Antibacterial activity, antibiotic retention, and infection resistance of a rifampin-impregnated gelatin-sealed Dacron graft. J Vasc Surg $1994 ; 19: 675-682$

6. Kieffer E, Bahnini A, Koskas F, Ruotolo C, LeVlevec D, Plissonnier D. In situ allograft replacement of infected infrarenal aortic prosthetic grafts: results in forty-three patients. J Vasc Surg 1993;17:349-355

7. Nevelsteen A, Feryn T, Lacroix H, Suy R, Goffin Y. Experience with cryopreserved arterial allografts in the treatment of prosthetic graft infections. Cardiovasc Surg 1998;6: 378-383 
We would like to thank Dr. Calligaro for his insightful comments. Although there are good results documented with the use of cryopreserved allografts for aortic infection, many questions still remain to be answered. Dr. Calligaro cites three main concerns. First, the good results of cryopreserved allografts may depend on the causative organism. In the small experience cited in the literature, it is difficult to draw conclusions, as there are often no organisms cultured, or the number of patients with identified bacteria is small. As we continue to acquire a data registry, we may be able to associate specific pathogens with success or failure of cryopreserved allograft replacement. Until we have this data, however, any conclusions would be speculative.

Second, Dr. Calligaro poses the question of storage techniques. Kieffer's series of 43 patients treated with aortic allografts stored at $4^{\circ} \mathrm{C}$ had good short-term results with a mean follow-up of 13.8 months, with a $12 \%$ postoperative mortality rate and only one aortic rupture secondary to infection. ${ }^{1}$ Kieffer's later paper of 83 patients reported one early aortic disruption resulting in death, four patients with allograft dilatation, three with allograft disruption requiring re-operation, and 19 late occlusive lesions. ${ }^{2}$ The purpose of cryopreservation is to maintain endothelial cell viability, which is eliminated in grafts stored at $4^{\circ} \mathrm{C}$ for one week. ${ }^{3}$ Preservation of endothelial cells may improve resistance to platelet-initiated thrombosis, and ultimately decrease the incidence of thrombotic allograft complications.

Finally, the question of availability must be considered. Despite the 24hour delay in obtaining a cryopreserved graft, this time period is an improvement on the 48-hour to 21 -day delay reported in Kieffer's series. ${ }^{1}$ As with any new technology, cryopreserved allografts offer a new option that may not be appropriate in every circumstance, such as an emergency aortic replacement. Such patients may be better served with extra-anatomic reconstruction, or with in-situ prosthetic replacement.

\section{REFERENCES}

1. Kieffer E, Bahnini A, Koskas F, Ruotolo C, Le Blevec D, Plissonnier D. In situ allograft replacement of infected infrarenal aortic prosthetic grafts: results in forty-three patients. J Vasc Surg 1993;17:349-355

2. Koskas F, Plissonnier D, Bahnini A, Ruotolo C, Kieffer E. In situ arterial allografting for aortoiliac graft infection: a 6-year experience. Cardiovasc Surg 1996;4:495-499

3. Boren CH, Roon AJ, Moore WS. Maintenance of viable arterial allografts by cryopreservation. Surgery 1978;83:382-391 
